\title{
Moctezuma, Miguel (2011), La transnacionalidad de los sujetos: Dimensiones, metodologías y prácticas convergentes de los migrantes en Estados Unidos, México: Universidad Autónoma de Zacatecas-Miguel Ángel Porrúa Editor.
}

E libro es una contribución relevante para la reflexión en este momento de incertidumbres, de tiempos nublados. En palabras del autor, la obra es fruto del esfuerzo de diez años de investigación sobre el tema migratorio, enfocado a las asociaciones de migrantes mexicanos en Estados Unidos.

Es una obra particularmente interesante porque hay una mezcla de interés científico, compromiso por la generación de nuevos conocimientos y por el futuro de los migrantes. Pocas veces se dice cómo se construye un libro, y aquí el autor plantea la ruta teóricometodológica, lo que es un aporte para los interesados en el fenómeno de la migración.

El autor advierte que no se trata de "un estudio convencional que seguramente suscitará controversias", que en realidad es una ganancia de todo ejercicio reflexivo. En efecto, el libro es un esfuerzo intelectual por comprender la naturaleza de las organizaciones de los migrantes. Es un trabajo que está basado en la observación directa, en la participación con las comunidades migrantes en el lugar de llegada pero también en el origen.

La parte teórico-conceptual es un buen ejercicio, una contribución sobre un terreno donde hasta ahora no hay consensos definitivos, pues tenemos que recordar que el objeto de estudio cambia constantemente, siempre está en movimiento. Creo que es un trabajo muy documentado y autocrítico, que reconoce sus alcances y limitaciones.

Abreva en varios campos del conocimiento, proponiendo una articulación entre ellos para entender mejor el fenómeno, lo que significa al mismo tiempo un distanciamiento con los enfoques especializados, centrados en una disciplina específica. En este ejercicio, como en todo trabajo serio, es ineludible retomar los aportes de otros, pero sobre todo de la experiencia directa de las organizaciones y, con ellas, las tareas de reflexión de su propia práctica.

Consecuente con la idea anterior, el autor afirma que "no existe una teoría de la migración ni es conveniente que exista". En esta misma línea de pensamiento, refiere que "tampoco es posible que se llegue a formular un marco teórico común para el estudio de la migración internacional". Para terminar de redondear esta idea señala que "el propio desarrollo de la ciencia lleva a la convicción de que los intentos por reconstruir un sólo modelo de explicación conduce a un rotundo fracaso, empobreciéndose con el intento de edificar 〈escuelas〉 de pensamiento único".

Es importante destacar el proceso mediante el cual se delimita el objeto de estudio: acercamiento progresivo, descartando la definición o conceptualización a priori. 
En este sentido, el autor inicia la investigación partir de su aproximación a la realidad y de la praxis de los sujetos migrantes, cuestión que lo lleva a delimitar el campo teórico-conceptual. La complejidad del fenómeno lo obliga a construir una tipología del migrante. En este sentido llama la atención la categoría de migrante de subsistencia y nos preguntamos: ¿Cuántos de estos se ubican en esta categoría en el mundo y en Estados Unidos en particular? Los hay también migrantes empresarios y exitosos, los que además, dice el autor, tienen buena presentación, portan computadoras y celulares.

Otro aspecto de relevancia en el ámbito teóricometodológico es la construcción de la Unidad de Análisis, aspecto medular en toda investigación porque de su construcción depende el tipo de resultados. En esta búsqueda, el autor distingue claramente dos Unidades: 1) clubes sociales; 2) asociación de clubes, ambas tienen grados de madurez diferenciados.

En el ámbito teórico-conceptual, el autor precisa el alcance de la categoría "transnacionalismo", un término que puede conducir a direcciones diversas y hasta contradictorias, dice el autor. Suele confundirse con la globalización en su versión homogeneizante. El autor parte de la idea de que el Estado-nación ha sido rebasado por la realidad, a la que se suma la globalización impulsada por los medios de comunicación y el transporte. Frente a esta nueva realidad surge la necesidad de desarrollar formas de pensamiento donde la reflexión de lo nacional recoja lo transnacional y viceversa, donde la transnacional no pierda de vista lo nacional. Una posición equilibrada que no niega la existencia del Estado-nación a pesar de sus transformaciones.

Otra cuestión interesante es la distinción que hace el autor entre transnacionalidad y transnacionalismo. El primero alude a las prácticas sociales que desarrollan los migrantes, y el segundo a las relaciones de identidad y pertenencia. ¿Cuál es la importancia de esta distinción? El autor refiere que "implica una delimitación sobre los sujetos de estudio, sus alcances y sus metodologías". En otras palabras, de acuerdo con el autor: a diferencia del transnacionalismo identitario, la transnacionalidad, aunque lo incluye, ha de moverse cuidadosamente entre las prácticas individuales y las prácticas colectivas.

El autor reconoce que el concepto de transnacionalismo ha sido utilizado con ambigüedad y que su popularidad puede convertirlo en un concepto vacío. Sin embargo, considera que hay avances significativos en la reflexión sobre el transnacionalismo, uno de los más notables es el reconocimiento de un campo social transnacional, con una dimensión social, económica, política y cultural. Según el autor, esta es una formulación correcta porque permite "avanzar en la transnacionalidad, destacando el desarrollo de las prácticas sociales, el cambio social, el cuestionamiento de las instituciones y sus normas".

Mediante los esquemas de genealogía el autor ilustra el movimiento y la conformación de la familia transnacional, el movimiento de destino y después de un periodo el de regreso al origen, al tiempo que se extiende la comunidad migrante con los primeros hijos que ya formaron un hogar. Este proceso puede ser objetivado en el concepto de familia ampliada transnacional, en él se reconoce el intercambio de valores.

Otro ámbito del análisis es la comunidad como relación social transnacional. Se le ha llamado espacio social transnacional, incluso formación social transnacional, pero en todo caso, de lo que se trata es de dar cuenta de una comunidad contextualizada como relación social, como expresa Portes.

También es importante destacar el campo de análisis en torno a la organización del migrante como sujeto social y político. El autor reconoce que este transnacionalismo "no ha podido echar raíces firmes" porque la concepción dominante está centrada en el individualismo y la perspectiva etnográfica. Me parece que este es un punto central donde se pone a prueba la tesis del transnacionalismo desde abajo, que se contrapone al transnacionalismo desde arriba, como 
una visión contestataria, de desafío a la globalización neoliberal.

Por otra parte, se destaca la crítica al "nacionalismo metodológico", que niega la simultaneidad de las prácticas culturales y de sobrevivencia en uno y otro lugar. Es interesante la posición del autor en el sentido de que la existencia del campo social transnacional no elimina la base nacional, por el contrario, lo nacional incluye parte sustantiva de lo transnacional, esto evita considerar la idea de que las fronteras nacionales han desaparecido y que nos encontramos frente a una ciudadanía cosmopolita o supranacional.

Más adelante, el autor analiza las asociaciones de migrantes mexicanos en Estados Unidos y formula la hipótesis según la cual los proyectos sociales son parte de un conjunto de prácticas que sólo son comprendidas a partir de la propia naturaleza social de estas organizaciones.

La contribución del libro en este terreno es que aporta elementos para el análisis de las organizaciones de migrantes, que indudablemente, permite entender la complejidad y la multidimensionalidad del fenómeno. De esta manera, el autor comienza por el análisis de los patrones migratorios y emprende una revisión de las contribuciones de diversos autores sobre el tema, donde se incluyen indicadores tales como: tipo de permanencia, establecimiento, estatus migratorio, formación de nuevos hogares.

Se reconocen las contribuciones de quienes han propuesto un proceso migratorio familiar que subsume las tipologías anteriores y que se pueden dividir en: a) migración gradual de la familia; b) migración unificada de la familia; y c) migración independiente. Una observación particularmente importante del autor, aunque aparentemente simple, es la siguiente: "sin el predominio de la migración establecida no es posible la existencia, crecimiento y desarrollo de las organizaciones de migrantes". El autor también se refiere a las redes sociales y una consideración fundamental que hace al respecto es que: "las redes sociales forman parte de las condiciones que hacen posible la reproducción social de vastos segmentos de la población en México".

De acuerdo con el autor, la trayectoria de la organización ha permitido pasar de la formación de clubes de migrantes a asociaciones de clubes, adquiriendo mayor solidez, presencia estable, formalizada, con amplia capacidad de negociación, que rebasa con mucho los confines de la comunidad y la entidad, incluso del país, para convertirse en sujeto social extraterritorial. Estamos pues en presencia de organizaciones sociales complejas.

El autor discute el origen de las inversiones sociales, que a diferencia de las remesas familiares, constituyen un fondo de ahorro y de uso colectivo, y se constituyen en una vía para ejercer la participación social de los migrantes. El origen de las remesas colectivas se sitúa en los años sesenta, pero se hacen visibles a partir de los noventa con la participación del gobierno. Esta observación es importante porque permite ver la trayectoria de la organización que se expresa en las remesas colectivas.

Un aspecto interesante del libro es el estudio de la morfología de las asociaciones de migrantes: identifica el nivel, los rasgos y los alcances de cada estructura organizativa hasta alcanzar su madurez como sujeto social. El método elegido es la teoría de conjuntos que permite identificar las uniones y relaciones. El análisis está centrado en la reflexión de los sujetos extraterritoriales y las prácticas de las organizaciones, poniendo el acento en el migrante colectivo como sujeto social, que finalmente lucha por la ciudadanía y por mantener y recrear la identidad propia.

Un apunte metodológico que llama la atención en la lectura del texto es el que se refiere al abordaje del tema de la transnacionalidad, trascendiendo el campo disciplinar pero también el de la multidisplina porque, esto último, según el autor, no hace otra cosa que mirar desde distintos miradores la realidad estudiada y de lo que se trata es de construir 
una mirada transversal o sintética que recoja la convergencia transdisciplinar.

El autor hace un recorrido en torno a la constitución del sujeto social, desde las primeras manifestaciones de remesas familiares destinadas al mejoramiento de las iglesias hasta la emergencia de organizaciones que rebasan el nivel comunitario, sustentadas en un tipo particular de migración. De manera que se distinguen las organizaciones de primer nivel, identificadas con los comités de pueblos cuya membresía es limitada y se caracterizan por su poca estabilidad.Las de segundo nivel se identifican con las asociaciones donde los migrantes mantienen relaciones y prácticas permanentes y que llegan a institucionalizarse. Aquí estamos frente a un nivel de organización de mayor complejidad, con estructuras permanentes, alto grado de formalización, reconocimiento y legitimidad.

En otro apartado, el autor centra sus esfuerzos en problematizar el significado social de las remesas familiares y colectivas. En este sentido es muy interesante saber lo que respondieron los migrantes sobre la ilusión de llegar a Estados Unidos. Los migrantes manifestaron la solidaridad como una de las expresiones afectivas. El envío de remesas denota un sentido de pertenencia y de solidaridad: 1) reafirman permanentemente las relaciones familiares, 2) aseguran la expresividad afectiva, 3 ) atienden diversas situaciones de emergencia, y 4) promueven la movilidad social en las comunidades de origen.

Más adelante, el autor presenta un estudio de caso donde, a través de la etnografía, se aborda la cultura de la migración y la comunidad migrante. Aquí vale la pena destacar dos ideas: la primera es construcción de la cultura de la migración, que según el autor, "se produce con el retorno del migrante y de sus descendientes, los gastos dispendiosos durante la navidad y la fiesta patronal, así como la celebración de una ceremonia religiosa como parte de las fiestas patronales. La cultura de la migración está asociada con la palabra norteño que sirve para designar a los que emigraron, los que se van y luego retornan, es la identidad de los otros.

Finalmente, el libro concluye con un capítulo dedicado al Rey del Tomate, Andrés Bermúdez, que simbolizó a los migrantes. El personaje encarnaba al migrante exitoso, el sueño de muchos migrantes que desean llegar a hacer fortuna del otro lado de la frontera, que su tierra les ha negado. En este caso también se le negó, aún con la fama y el dinero, la posibilidad de llegar a ocupar un puesto de elección popular.

En resumen, considero que el libro es muy importante tanto para los que se inician en los temas migratorios como para los que ya tienen una larga experiencia, porque hay aportes importantes, preguntas y tesis que generan controversia. El texto genera nuevas preguntas y esto es lo más importante en la investigación.

De la lectura del libro me surgen las siguientes preguntas: ¿Cuáles son sus alcances de la práctica transnacional? ¿Hasta dónde se cuestiona a las instituciones? ¿Cuál es la naturaleza del cambio social impulsado por la transnacionalidad? Un par de preguntas específicas sobre los jóvenes migrantes de las últimas olas migratorias previo a la crisis de 2008 son: iEl joven le importa el destino de su comunidad? ¿Para este joven migrante existe la comunidad? ¿No es una exageración hablar de ciudadano transnacional o ciudadanía sustantiva cuando, tanto en el lugar de destino como de origen, se le niegan los derechos básicos, hasta de manifestación, sobre todo a ese migrante de "subsistencia"? ¿Qué efecto ha tenido el neoliberalismo en la formación de redes y de organizaciones de migrantes que desembocan en el transnacionalismo y la transnacionalidad? No debemos olvidar que la ideología del neoliberalismo genera un individualismo exacerbado que se expresa en prácticas poco solidarias, ¿En qué medida las remesas colectivas han disminuido por efecto del neoliberalismo?

El autor plantea una idea fundamental, dice: para la mayoría de los estudiosos, las prácticas de los migrantes 
siguen orientándose sólo a México. El autor señala que esto no es cierto del todo. Si esto es así, surge la pregunta ¿Cuáles son los límites del transnacionalismo, de la ciudadanía transnacional ¿Qué pasó con las manifestaciones del 1 de mayo de 2006, con los 400 mil manifestantes en Chicago, los 75 mil en Denver, y las decenas de miles que protestaron en Nueva York, Los Ángeles y otras tantas ciudades de la Unión Americana? ¿Qué acciones desarrollaron los migrantes con la crisis de 2008 y 2009, y ahora con los ocupas en Wall Street? ¿Cuáles son los límites de las organizaciones de migrantes en Estados Unidos? Estas son algunas de las preguntas que surgen de la lectura del interesante texto de Miguel Moctezuma, un texto muy recomendable para el análisis de las migraciones en el siglo XXI.

Daniel Villafuerte Solís Investigador de Tiempo completo en CESMECA-UNICACH 